\title{
Gastric-and-intestinal mixed-type intestinal metaplasia: aberrant expression of transcription factors and stem cell intestinalization
}

\author{
Tetsuya Tsukamoto, Tsutomu Mizoshita, and Masae Tatematsu \\ Division of Oncological Pathology, Aichi Cancer Center Research Institute, 1-1 Kanokoden, Chikusa-ku, Nagoya 464-8681, Japan
}

\begin{abstract}
Helicobacter pylori plays a causative role in the development of chronic atrophic gastritis, intestinal metaplasia (IM), and stomach cancer. Although IM has long attracted attention as a putative preneoplastic lesion for stomach cancers, its clinicopathologic significance has yet to be clarified in detail. Using gastric and intestinal epithelial cell markers, IM was here divided into two major types: a gastric-and-intestinal (GI) mixed type and a solely intestinal (I) type. In the former, gastric and intestinal phenotypic markers appeared not only at the glandular but also at the cellular level. Furthermore, neuroendocrine cells also showed intestinalization along with their exocrine counterparts. In animal models, GI-type IM was found to appear first, followed by the solely I type. Summarizing these data, it was suggested that IM might be caused by the gradual intestinalization of stem cells from the GI to the I type. The molecular mechanisms of IM include the ectopic expression of CDX1, CDX2, OCT-1, and members of the Erk pathway. Suppression of the expression of gastric transcription factors such as SOX2, genes that are involved in the Sonic hedgehog pathway, and RUNX3, a tumor suppressor gene, could be additional relevant alterations. The expression of PDX1 may also be associated with pseudopyloric gland metaplasia and IM. Detailed analysis of gene regulation may shed light on the molecular bases of gastric lesions, leading to strategies for chemoprevention.
\end{abstract}

Key words Gastric-and-intestinal mixed-type intestinal metaplasia $\cdot$ Stem cell $\cdot$ Transcription factor

\section{Introduction}

Since the discovery of Helicobacter pylori by Warren and Marshal [1] in Australia, it has been well established that this microorganism plays important roles in the development of chronic gastritis, intestinal metaplasia (IM), and stomach cancers, including malignant lym-

Offprint requests to: T. Tsukamoto

Received: March 10, 2006 / Accepted: March 20, 2006 phomas [2-7]. In 1994, the World Health Organization (WHO)/International Agency for Research on Cancer (IARC) categorized $H$. pylori as a group 1 "definite carcinogen" [8]. IM has been extensively studied as a putative preneoplastic lesion in the human stomach, due to its strong association with stomach cancer development [9-18]. Although controversy exists as to its real significance $[19,20]$, IM is considered by some to be a precancerous lesion for so-called intestinal adenocarcinomas of Lauren's classification [21]. This type comprises well- and moderately differentiated adenocarcinomas, irrespective of the presence of the intestinal properties. Clearly, the pathogenesis of IM, as well as its molecular background, needs to be detailed for the elucidation of the actual relation between IM and stomach cancer [22].

\section{Stem cells in the gastrointestinal mucosa}

To investigate the cellular origin of tissues, mosaicism of cellular genetic markers is often used. One approach is to use chimeric animals, produced experimentally by the amalgamation of cells from allelically different strains. Recently, numerous histological markers have also been applied for the analysis of mosaicism in chimeric mice. Antibodies strictly recognizing $\mathrm{C} 3 \mathrm{H}$ strain-specific antigens (CSAs) [23] enable the immunohistochemical discrimination of $\mathrm{C} 3 \mathrm{H}$ cells in histological sections of chimeric mouse tissues. In normal gastric and intestinal mucosa of chimeric mice, each gland is composed entirely of CSA-positive or -negative cells, and no mixed glands are found, indicating that each individual gland in the adult mouse is derived from a single progenitor cell. Surface mucous cells (foveolar epithelial cells), mucous neck cells, parietal cells, and chief cells in the fundic glands thus all arise from the same cell. Similarly, surface mucous cells and pyloric gland cells arise from a single progenitor cell [24-26]. 


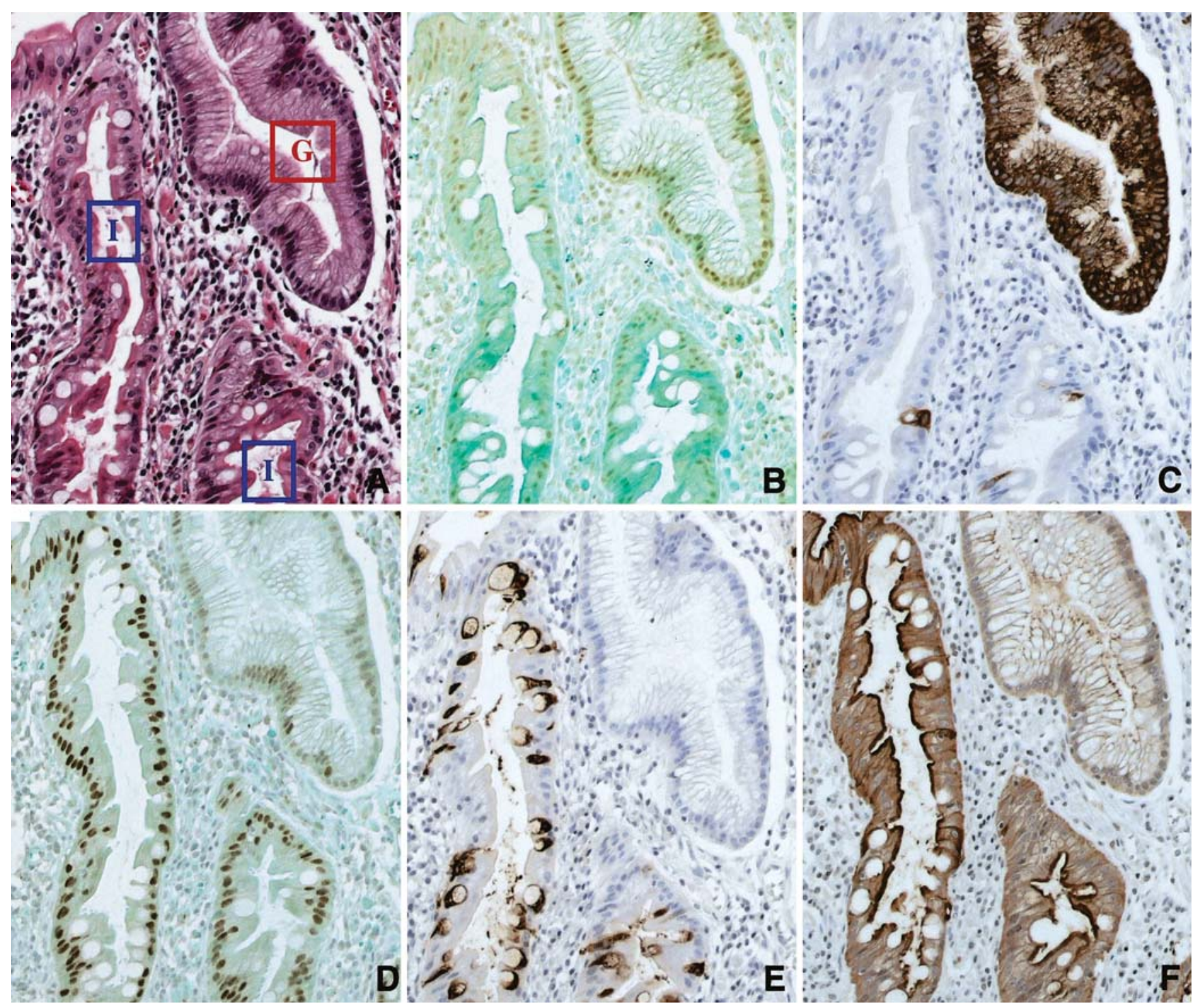

Fig. 1A-F. Immunohistochemical staining of normal human gastric mucosa and intestinal metaplasia. $G$, Pyloric gland with a gastric phenotype expressing Sox2 and MUC5AC; I, intestinal metaplastic gland harboring goblet cells producing Cdx2, MUC2, and villin. A H\&E staining; B-F immunohistochemistry; for Sox2 (B), MUC5AC (C), Cdx2 (D), MUC2 (E), and villin (F). Binding was visualized with 3,3'-diaminobenzidine (DAB), and counterstaining was done with light green SF yellowish (B) or hematoxylin $(\mathbf{C}-\mathbf{F}) . \times 200$

Another approach to showing cellular phenotypic mosaicism in females utilizes the random inactivation of one X chromosome [27-29]. The human androgen receptor gene locus (HUMARA) has been used to assess methylation, and about half of intestinal metaplastic glands were revealed to be heterotypic (comprised of cells with differing allelic methylation), while the remainder were homotypic (cell populations with the same allelic methylation). Mouse models have also been used to show heterogeneity within a single gland/crypt, utilizing the Dlb-1 locus, which determines the expression of the binding site for the lectin Dolichos biflorus agglutinin (DBA) in the intestinal epithelium, in
C57BL/6J x SWR F1 mice [30]. Mouse models have also shown X-linked glucose-6-phosphate dehydrogenase (G6PD) activity in $\mathrm{C} 3 \mathrm{H} / \mathrm{Heston}$ mice [31]. When a carcinogen, ethylnitrosourea, was administered to the $\mathrm{C} 3 \mathrm{H} / \mathrm{Hester}$ mice, loss of G6PD activity appeared in one side of a colonic crypt [31]. These results led to the hypothesis of the existence of four to six stem cells in one crypt [32].

The discrepancy between the concept of a single progenitor stem cell and the hypothesis of four to six stem cells in one crypt could be derived from confusion regarding the terminology used for "stem cells". The single stem cell in glands/crypts hypothesized from the 

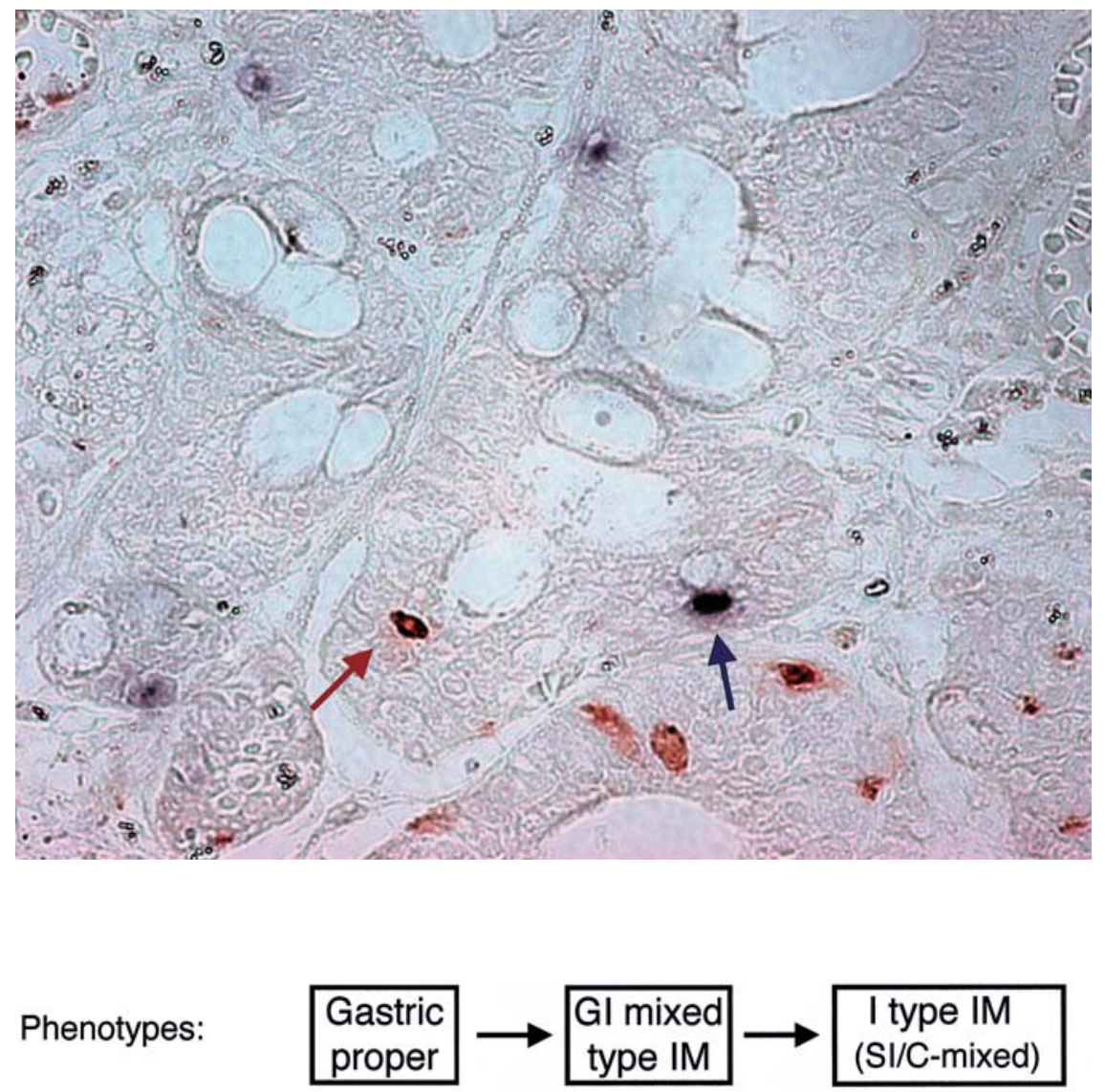

\section{Expression of differentiation markers:}

\section{Expression of transcription factors:}

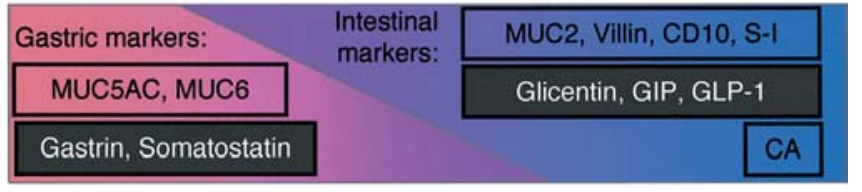

Cdx2

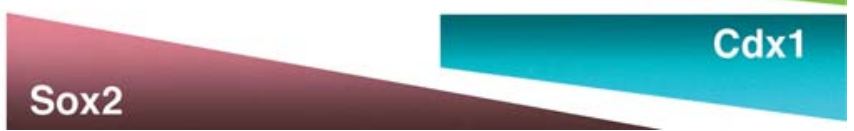

Fig. 2. An example of double staining of gastrin and glucagon-like peptide (GLP)1 in gastric-and-intestinal mixed phenotype intestinal metaplasia (GI-IM). A mixture of gastrin- and GLP-1-positive endocrine cells is apparent in the same gland. Gastrin-positive cells (blue arrow) and GLP-1-positive cells (red arrow) are indicated. $\times 200$
Fig. 3. Schematic view of progression of intestinal metaplasia $(I M)$. Gastric mucosa changes to gastric-and-intestinal $(G I)$ mixed-type IM, and then progresses to Solely intestinal $(I)$-type IM. Within the I type, small-intestinal $(S I)$ type cells can colocalize with $\mathrm{G}$ phenotype cells, whereas colonic $(C)$ type cells appear in complete I-type IM. Sox2, along with gastric markers, is decreased, and Cdx and intestinal markers emerge ectopically during the progression of IM. $S-I$, sucrase-isomaltase; $C A$, carbonic anhydrase 1; GIP, gastric inhibitory peptide chimeric mouse data may be a "master stem cell" commanding the whole gland, whereas the four to six stem cells in one crypt, indicated by the latter experiments $[31,32]$, could be "committed stem cells", obeying the master stem cell in producing their progeny.

\section{Gastric and intestinal epithelial cell markers}

Mucins in the alimentary tract can be divided into two main classes: class III mucins in mucous neck cells, pyloric gland cells, and Brunner's gland cells; and class II mucins, in surface mucous cells, goblet cells, and the surface coat of intestinal absorptive cells, as assessed utilizing paradoxical concanavalin A staining [33]. With more recent developments in mucin histochemistry and immunohistochemistry, intestinal metaplastic cells can now be clearly classified, by the analysis of phenotypic expression, into a gastric epithelial cell type ( $G$ type), resembling pyloric gland cells and surface mucous cells, and an intestinal epithelial cell type (I type), resembling goblet and intestinal absorptive cells. Gastric mucosa consists of foveolar cells in the upper two-thirds and pyloric gland cells in the lower one-third. Concerning gastric phenotypic markers, the surface mucous-cell type contains galactose oxidase-Schiff (GOS) and sialidaseGOS reactive mucin, positive for mucin core protein (MUC), MUC5AC. Cells of the pyloric gland cell type 
contain class III mucin, colocalized with MUC6, and show pepsinogen reactivity. Intestinal metaplastic mucosa consists of absorptive cells with a brush border, goblet cells packed with clear rounded vacuoles containing mucin, and, sometimes, Paneth cells, harboring eosinophilic granules in their cytoplasm, which usually appear at the bottom of the glands. Regarding intestinal markers, the goblet-cell type contains mucin that is GOS-negative and sialidase-GOS reactive, possessing sialyl-Tn antigen and MUC2 core protein. Cells of the intestinal absorptive type demonstrate sucrase and intestinal-type alkaline phosphatase activity, harboring CD10 as a surface marker, and the structural protein villin. Cells of Paneth-cell type are reactive with anti-defensin antibodies [34-41] (Fig. 1, Table 1).

\section{Classification of intestinal metaplasia (IM)}

The present widely applied classification of IM, into complete and incomplete types, was first proposed by Matsukura and colleagues [10] and Kawachi and colleagues [42]. Classification based upon mucin secretion patterns as well as morphology has also allowed division into a small-intestine type and a colonic type [43,44]. Jass and Filipe [45] described three grades of IM (types I, II, and III) on the basis of morphology and classical mucin staining, using periodic acid-Schiff, Alcian blue $(\mathrm{AB})$, and high iron diamine (HID) methods. Type I corresponds to the complete type and types II and III to the incomplete type. While these classifications are generally accepted, they are based only upon the intestinal properties and do not take into account the gastric properties that are still preserved in association.

We have therefore proposed a new classification, based upon the cell differentiation status, using both gastric and intestinal cell phenotypic markers [39]. With this classification, IM is divided into two major types; a gastric-and-intestinal (GI) mixed type, and a solely intestinal (I) type. To confirm this histological classification, stomach mucosa was subjected to gland isolation and classification of individual glands into gastric $(\mathrm{G})$, GI mixed, and I types according to the preservation of pyloric cells and the appearance of goblet cells, as revealed with Alcian blue and paradoxical concanavalin A staining. The $\mathrm{G}$ type preserves the pyloric cells without the emergence of goblet cells. In the I type, intestinal metaplastic glands consist of goblet and intestinal absorptive cells, with or without Paneth cells. In the GI mixed-type, on the other hand, gastric phenotype cells are found together with intestinal phenotype cells in various-combinations. All of the subtypes of GI mixedtype IM and a subtype of the I type without Paneth cells belong to the incomplete IM category, while the I type with Paneth cells corresponds to complete-type IM. In many cases of the GI mixed type, atrophied pyloric glands are present under the intestinalized glands.

Mixtures of gastric and intestinal phenotypes occur at the cellular as well as the glandular level. Intestinal metaplastic glands are easily found on hematoxylin and eosin (H\&E) staining, by the presence of goblet cells and brush border lining the apical side of the epithelium. Goblet cells have been confirmed to show an intestinal phenotype, as shown with MUC2 immunostaining, which is not present in gastric epithelium. The brush border is positive for villin, as shown in normal intestinal epithelium. However, gastric mucin sometimes remains in both goblet and absorptive cells, as revealed by MUC5AC immunohistochemistry, with villin expression being weaker in MUC5AC-positive cells as compared to those without MUC5AC expression. Thus, IM subtypes should not be considered as independent entities, but, rather, as a sequence of pathological states with a gradual change from gastric to intestinal character. GI mixed-type IM may be composed of mixtures of cells with various degrees of intestinal phenotypic shift, rather than being just a random mixture of gastric- and intestinal-type cells. This allows us to introduce the notion that IM may be due to abnormal stem cell differentiation, but with some stem cells still obeying certain orders.

It is believed that stem cells (multipotent progenitor cells) are present in the proliferative cell zone in the isthmus region of gastric glands, giving rise to all the various cell types by differentiation, so that, consequently, gastric glands are monoclonal in the adult stage $[46,47]$. In the environment of a normal gastric gland, cells derived from stem cells undergo complex bipolar migration from the isthmus, either upward or downward. In the pyloric mucosa, surface mucous cells move upward, while pyloric gland cells migrate downward [48]. In the crypts of the small intestine, on the other hand, stem cells would be expected to be present in the proliferative cell zone at the bottom of the crypts. In the normal intestinal gland, cells that will become absorptive and goblet cells move up, and only those differentiating into Paneth cells migrate lower from the proliferative cell zone. In GI mixed-type IM, gastric surface mucous cells, intestinal absorptive cells, and goblet cells are found in the glandular portions above the proliferative zone, while pyloric gland cells and Paneth cells are found in the lower glandular portions, below the proliferative zone [40]. GI mixed-type IM may be the consequence of the abnormal differentiation of stem cells that can produce both gastric- and intestinal-type cells, with the normal cell migration pattern preserved. Because epithelial cell differentiation and the migration of gastric glands are thought to be closely linked, it is not clear why only the former is disturbed. 
Table 1. Differentiation markers for the human gastrointestinal tract

Differentiation markers

\section{Gastric}

Fundic

mucous

neck cell
Fundic

chief cell
Fundic parietal cell

\title{
Structural \\ proteins
}

Functional

proteins

Proton pump alpha subunit ${ }^{c}$

Proton pump beta subunit $^{\mathrm{c}}$

\section{Enzymes}

Pepsinogen $\mathrm{II}^{\mathrm{e}}$

\author{
Pepsinogen $\mathrm{I}^{\mathrm{f}}$ \\ Pepsinogen II
}

\begin{tabular}{|c|c|c|c|}
\hline $\begin{array}{c}\text { Mucin core } \\
\text { proteins }\end{array}$ & MUC5AC & MUC6 $^{\mathrm{a}}$ & MUC6 $^{\mathrm{a}}$ \\
\hline Mucins & $\begin{array}{l}\text { HGM }^{\text {a }} \\
\text { SH9 } \\
\text { GOS staining }\end{array}$ & PCS & \\
\hline
\end{tabular}

\section{Neuroendocrine} hormone

\begin{tabular}{|c|c|c|}
\hline $\begin{array}{l}\text { Transcription } \\
\text { factors }\end{array}$ & Sox $2^{j}$ & $\mathrm{Pdx} 1^{\mathrm{n}}$ \\
\hline
\end{tabular}

HGM, human gastric mucin; GOS, galactose oxidase Schiff staining; PAS, periodic acid Schiff staining; PCS, paradoxical concanavalin A staining; I-ALP, intestinal alkaline phosphatase; CA1, carbonic anhydrase 1; SIMA, small intestinal mucious antigen; S-GOS, sialidase GOS; GIP, gastric inhibitory peptide; GLP-1, glucagon-like peptide 1

Sources of available antibodies

${ }^{a}$ Novocastra (Newcastle upon Tyne, UK)

${ }^{\mathrm{b}}$ Transduction Laboratory (Lexington, KY, USA)

${ }^{\mathrm{c}}$ Medical and Biological Laboratories (MBL) (Nagoya, Japan)

${ }^{\mathrm{d}}$ Dr. E. M. Porter, University of California, Los Angeles

${ }^{\mathrm{e}}$ Biogenesis (Poole, England, UK)

${ }^{\mathrm{f}}$ Dr. M. Ichinose, Wakayama Medical College

${ }^{\mathrm{D}} \mathrm{Dr}$. T. Irimura, Tokyo University

${ }^{\mathrm{h}}$ DAKO (Glostrup, Denmark)

${ }^{i}$ Dr. K. Hirano, Gifu Pharmaceutical University

jChemicon (Temecula, CA, USA)

${ }^{\mathrm{k}}$ Dr. Imai, Nara Medical College

${ }^{1}$ Dr. S. Hakomori (Tokyo University)

${ }^{\mathrm{m}}$ Yanaihara Institute (Fujinomiya, Shizuoka, Japan)

${ }^{n}$ Dr. Y. Yuasa, Tokyo Medical and Dental University

${ }^{\circ}$ Dr. Y. Ito, Institute of Molecular and Cell Biology, Singapore

p Biogenex (San Ramon, CA, USA) 


\section{Neuroendocrine}

cell

Absorptive cell

Goblet cell

Paneth cell

Neuroendocrine

CD10 ${ }^{\mathrm{a}}$

Villin $^{\mathrm{b}}$

\section{Defensin $5^{\mathrm{d}}$}

Sucrase-
isomaltase
I-ALP $^{\mathrm{i}}$
CA1 $^{\mathrm{j}}$

Lysozyme $^{\mathrm{h}}$

MUC2 $^{\mathrm{a}}$

SIMA $^{\mathrm{a}}$

TKH2 ${ }^{1}$

Sialyl-Tn antigen ${ }^{1}$

$91.1 \mathrm{H}^{\mathrm{g}}$

S-GOS staining

Alcian blue staining

Chromogranin $\mathrm{A}^{\mathrm{h}}$

Chromogranin $\mathrm{A}^{\mathrm{hl}}$

Gastrin $^{1}$

Somatostatin $^{\mathrm{h}}$

Glicentin ${ }^{1}$

GIP

GLP-1 ${ }^{1}$

\section{Cdx1}

$\mathrm{Cdx} 2^{\mathrm{p}}$
Cdx1

$\mathrm{Cdx} 2$
Cdx1

$\mathrm{Cdx} 2$ 


\section{Sequential analysis using animal models}

Experimentally, the shift from GI mixed-type IM to Itype IM can be observed in sequential observations in animal models. The occurrence of IM in rats gradually increases with time after X-ray irradiation; the number of GI mixed-type IMs is relatively high at 2-4 weeks, becoming lower thereafter. On the other hand, the number of I-type IMs is extremely low at 2 weeks, and then increases with time. These observations suggest that the phenotype of IM sequentially changes from the GI mixed-type to the I type [49].

H. pylori infection in Mongolian gerbils causes IM in their glandular stomachs [50]. Twenty-five weeks after inoculation with $H$. pylori, the glandular stomach epithelium becomes hyperplastic, and heterotopic proliferating glands (HPGs) penetrate the muscularis mucosae. Fifty weeks after infection, intestinal metaplastic cells appear among gastric epithelial cells, including goblet cells possessing Alcian blue-positive mucins and/or absorptive cells with a striated brush border, so that the lesions are characterized as GI-mixed-type IM. At 75 weeks, HPGs with gastric phenotype decrease and most animals possess solely I-type HPGs. Paneth cells appear by 100 weeks.

The $N$-methyl- $N$-nitrosourea-induced mouse stomach carcinogenesis model also provides support for the conclusion that intestinalization of the stomach epithelium occurs in late stages, as assessed by monitoring intestinal alkaline phosphatase expression [51].

\section{Coexistence of gastric- and intestinal-type endocrine cells in gastric-and-intestinal mixed-type intestinal metaplasia (IM) of the human stomach}

Gastrointestinal glands possess neuroendocrine cells, usually in their bottom regions, among the mucous and absorptive cells. Gastrin-positive endocrine cells are predominantly detected in the normal pyloric mucosa, with some detected in the duodenal mucosa. Somatostatin-positive cells are also mainly detected in the normal pyloric mucosa, with some detected in the fundic and duodenal mucosae. Glicentin, gastric inhibitory peptide (GIP)-, and glucagon-like peptide 1 (GLP-1)positive endocrine cells are detected exclusively in the duodenum, small intestine, and colon, but not in the normal gastric mucosa. Therefore, gastrin and somatostatin could be gastric-predominant endocrine cell markers, whereas glicentin, GIP, and GLP-1 characterize the intestinal phenotype.

In GI mixed-type IM glands, both gastric and intestinal endocrine markers have been found to be present in endocrine cells, correlating with the phenotypic expres- sion of the glands. Thus, in I-type IM glands harboring only intestinal mucous cell markers, endocrine cells demonstrate only intestinal endocrine peptides. However, double immunostaining for gastrin and GLP-1 has revealed the existence of both gastric and intestinal endocrine cells in the same glands of the GI-mixed-IM type. Furthermore, at the single cell level, quite a few glands harbored endocrine cells that were positive for both gastrin and GLP-1 (Fig. 2).

All of the different types of mucous, absorptive, and endocrine cells in normal as well as intestinal metaplastic glands may be derived from a single progenitor cell. In the light of the clonal findings with $\mathrm{C} 3 \mathrm{H} /$ $\mathrm{HeN} \leftrightarrow \mathrm{BALB} / \mathrm{c}$ chimeric mice, we consider that the alteration from gastric to intestinal metaplastic glands must be controlled at the stem-cell level.

\section{Expression of transcription factors in intestinal metaplasia (IM)}

\section{CDX homeobox gene family}

Caudal-type homeobox $(C d x) 1$ and $C d x 2$ are mammalian members of the caudal-related homeobox gene family [52]. In the adult mouse, and in humans, expression is strictly confined to the gut, from the duodenum to the rectum. Silberg et al. [53] reported the presence of $\mathrm{Cdx} 1$ protein in intestinal metaplastic lesions of the human stomach, and Mizoshita et al. [54] demonstrated the expression of $C d x 1$ and $C d x 2$ in both the small and large intestine, and in intestinal metaplastic mucosa of the human stomach. Eda et al. [55] found that the expression of $C d x 2$ preceded that of $C d x 1$ during the progression of IM. Satoh et al. [56] described $C d x 2$ expression in the gastric epithelium of $H$. pylori-infected patients, with or without obvious IM. $C d x 2$ plays an important role in the intestinespecific expression of carbonic anhydrase 1 [57]. Furthermore, it stimulates the intestine-specific expression of sucrase-isomaltase [58], lactase-phlorizin hydrolase [59], and guanylyl cyclase C [60]. More recently, $C d x 2$ has been revealed to induce the expression of MUC2 mucin in goblet cells [61]. Cdx1 has been reported to appear in intestinal metaplastic glands, as described by Silberg et al. [53]. Its expression is strong in regenerating epithelial foci, but not in quiescent sterilized crypts after irradiation-induced damage [62], and recent analyses have shown that $\mathrm{Cdx} 1$ is a direct transcriptional target of the Wnt $\beta$-catenin signaling pathway during mouse gut development [63] and that $\mathrm{Cdx} 1$ is stimulated by oncogenic $\beta$-catenin in human colon cancer cells [64]. Dietary factors may be involved in the suppression of $C d x 2$ via its promoter methylation [65] (Fig. 3). 


\section{Sox gene family}

To analyze the shift from a gastric to an intestinal phenotype, one should also focus on gastric transcription factors, including the Sox gene family [66], which consists of ten subgroups, divided according to Sry-like high-mobility group (HMG) box homology. The Sox genes in group B1, including Sox1, Sox2, and Sox3, are important for gut development in mice [67]. Insitu analysis of the chicken cSox2 gene demonstrated localized expression in the embryonic endoderm, with transcripts appearing before the commencement of morphogenesis, and cytodifferentiation in the rostral gut epithelium from the pharynx to the stomach. The caudal limit of $c$ Sox 2 expression coincides with that of the region competent for proventricular differentiation and with the rostral limit of the domain of $C d x A$ [68]. In the human digestive tract, Sox 2 expression is found in stomach epithelium, including the fundic and pyloric mucosae, but is very low in the intestine, as observed in the chicken. However, in IM, Sox2 transcripts begin to decrease and gradually disappear as IM progresses from the GI-mixed-type to the I type, with Sox2 showing an inverse correlation with $C d x 1$ and $C d x 2$. Sox 2 may regulate the expression of gastric differentiation markers, including MUC5AC, as suggested in the chicken system [69]. The expression patterns of Sox 2 and $C d x 1 / C d x 2$ are inversely related, and downregulation of Sox 2 could thus be an important mechanism in IM, in addition to the ectopic expression of $C d x 1 / C d x 2$ [70]. Specificity of the expression pattern of these transcription factors also persists in stomach cancers [71,72] (Fig. 3).

\section{$P D X 1$}

Pancreatic-duodenal homeobox 1 (PDX1), a ParaHox gene which contributes to the genesis and development of the pancreas, duodenum, and antrum, has been found to be frequently expressed in pseudopyloric glands and IM. MUC6 is more abundant than MUC5AC in pseudopyloric glands, while higher levels of MUC5AC than MUC6 are evident in IM. In carcinomas, $P D X 1$ expression is closely associated with MUC6, whereas no link is apparent between $P D X 1$ and MUC5AC reactivity. Thus, $P D X 1$ may play an important role in the development of pseudopyloric glands and subsequent IM $[73,74]$.

\section{OCT-1}

OCT-1 is a member of the POU homeodemain family of transcription factors [75]. This protein recognizes the canonical octamer motif (ATGCAAAT) and is implicated in the activation of the mouse $\mathrm{Cdx} 2$ promoter in pancreatic and intestinal cell lines. OCT-1 is expressed in chronic gastritis, particularly when it is adjacent to IM, and it is also expressed in $87 \%$ of IM foci. Furthermore, $74 \%$ of gastric carcinomas in one series were found to be positive for OCT-1, and a strong association was observed between OCT- 1 expression and an intestinal-type phenotype. OCT- 1 is able to bind to the CDX2 promoter, although transactivation of CDX2 has not been demonstrated [76].

\section{Sonic hedgehog (Shh) pathway}

High levels of $S h h$ are expressed in the fundic glands of the stomach in the normal gastrointestinal tract, but Shh expression is lost in IM of the human stomach [77], resulting in a glandular phenotype of intestinal transformation and overgrowth. Hedgehog-related transcription factors, Gli2 and Gli3, may be involved in Shh signaling. While disruption of Gli2 (the principal factor mediating the activator function of Shh), leads to minimal changes in glandular development in the mutant mouse, knockout of Gli3, functioning as a repressor of the Hedgehog signal, causes a striking phenotype of glandular expansion and intestinal transformation. A reduction in apoptotic events was seen in the stomachs of all Gli3 mutants, without affecting proliferation [78]. In humans, impaired expression of the gastric morphogenic factor Shh by parietal cells, and the increased expression of transcriptional activators of intestinal and pancreatic differentiation; namely, $C D X 2$ and $P D X 1$, seem to be crucial for the development of gastric atrophy and for intestinal, endocrine, and pancreatic transdifferentiation processes [74].

\section{Erk pathway}

The increased expression of villin is one of the earliest changes seen in $H$. pylori infection [70]. These bacteria have been found to stimulate the villin promoter in a human gastric adenocarcinoma cell line (AGS) via activation of the Erk pathway, where Elk-1 and the serum response factor (SRF) are downstream transcriptional targets. Inducible binding of Elk-1 and the SRF to the proximal promoter of villin after 3 and $24 \mathrm{~h}$ of treatment with $H$. pylori suggests that these bacteria alone are sufficient to initiate a cascade of signaling events responsible for villin expression.

\section{Runt-related transcription factor gene 3 (RUNX3)}

The RUNX family of transcription factors plays pivotal roles during normal development and in neoplasias [79], and $R U N X 3$ is reported to be a tumor suppressor gene for stomach cancer [80]. The loss of $R U N X 3$ expression due to aberrant methylation of its $\mathrm{CpG}$ island (evident in gastric cancer cell lines) suggests that this factor is a 
target for epigenetic gene silencing in gastric carcinogenesis. RUNX3 methylation has also been found in mucosa with chronic gastritis or IM [81]. Immunohistochemistry disclosed RUNX3 protein in most chief cells and a few gastrin-containing $G$ cells in normal mucosa, but not in IM or carcinoma cells [82]. Furthermore, in vitro studies have shown that gastric epithelial cells can differentiate into intestinal-type cells, probably due to the expression of $C d x 2$, when the function of Runx3 is impaired in Runx3-knockout mice [83].

\section{Expression of small-intestinal and colonic phenotypes in complete intestinal metaplasia (IM)}

Jass and Filipe [45] described three grades of IM, in terms of small-intestinal sialomucin and colonic sulfomucin expression, shown by high-iron diamine alcian blue (HID-AB) staining. Type I glands have no mucins in columnar cells, but feature goblet cells. Type II glands have blue-stained columnar cells possessing sialomucins, while type III glands harbor brown-stained columnar cells producing sulfomucins, with type II and III glands characterized by slight distortion. To discriminate small-intestinal and colonic differentiation in IM, molecular markers, including sucrase and carbonic anhydrase 1 (CA1) could be utilized in comparison with MUC5AC mucin core protein. CA1 expression is detectable in the cytoplasm of colon epithelial cells (especially on the luminal side of the colonic mucosa), but not in the jejunum. Sucrase, on the other hand, is present on the luminal surfaces of mature small-intestinal absorptive cells, but not in the colon. In IM, gastric MUC5AC expression is higher in CA1-negative mucous cells of GI-mixed-type IM glands, compared with CA1-positive I-type IM, in line with levels of MUC5AC mRNA. In contrast, the expression of sucrase is more strongly detected on the luminal surfaces of CA1-positive IM gland cells than in CA1-negative IM glands. MUC2, villin, and $C d x 2$ expression is observed in intestinal metaplastic cells, irrespective of CA1 expression. The number of glands with CA1 expression is higher in type I complete IM compared to types II and III incomplete IM. Furthermore, there appear to be no differences between types II and III in terms of CA1 expression, and no correlation of colonic sulfomucin expression. In short, the expression of gastric and colonic markers may be regulated in a different manner, although both can be colocalized with small-intestinal markers [84] (Fig. 3).

\section{Conclusion}

Atrophic gastritis and IM of the stomach mucosa are generally considered to be precancerous lesions, and chronic $H$. pylori infection is one of the most important factors in their development. However, H. pylori strains show a wide variety at the genome level, especially regarding the cag and vac genes, and this variation may underlie the observed large differences in stomach cancer incidence and mortality around the world, including the "Asian paradox" and "African enigma". In addition to bacterial factors, polymorphisms in host genes (for example, for cytokines that modulate inflammatory responses) are believed to exert synergistic effects. For the prevention of detrimental changes in the stomach mucosa, it is necessary to elucidate the pathogenetic mechanisms of mucosal atrophy and IM due to $H$. pylori infection.

Acknowledgments The authors thank colleagues in their laboratory for their expert technical assistance and valuable discussion. This work was supported in part by a Grant-in-Aid for the Third-term Comprehensive 10year Strategy for Cancer Control, and a Grant-in-Aid for Cancer Research, both from the Ministry of Health, Labour, and Welfare, Japan; and a Grant-in-Aid from the Ministry of Education, Culture, Sports, Science, and Technology of Japan.

\section{References}

1. Warren JR, Marshall BJ. Unidentified curved bacilli on gastric epithelium in active chronic gastritis. Lancet 1983;1:1273-5.

2. Forman D, Newell DG, Fullerton F, Yarnell JW, Stacey AR, Wald N, et al. Association between infection with Helicobacter pylori and risk of gastric cancer: evidence from a prospective investigation. BMJ 1991;302:1302-5.

3. Nomura A, Stemmermann GN, Chyou PH, Kato I, Perez-Perez GI, Blaser MJ. Helicobacter pylori infection and gastric carcinoma among Japanese Americans in Hawaii. N Engl J Med 1991;325:1132-6.

4. Parsonnet J, Friedman GD, Vandersteen DP, Chang Y, Vogelman JH, Orentreich N, et al. Helicobacter pylori infection and the risk of gastric carcinoma. N Engl J Med 1991;325:1127-31.

5. Uemura N, Okamoto S, Yamamoto S, Matsumura N, Yamaguchi $\mathrm{S}$, Yamakido $\mathrm{M}$, et al. Helicobacter pylori infection and the development of gastric cancer. N Engl J Med 2001;345:7849 .

6. Sepulveda AR, Coelho LG. Helicobacter pylori and gastric malignancies. Helicobacter 2002;7(Suppl 1):37-42.

7. Walker MM. Is intestinal metaplasia of the stomach reversible? Gut 2003;52:1-4.

8. IARC Working Group on the Evaluation of Carcinogenic Risks to Humans: Infection with Helicobacter pylori. In: Schistosomes, Liver Flukes and Helicobacter pylori, IARC Monographs on the Evaluation of Carcinogenic Risks to Humans, Vol. 61. World Health Organization/International Agency for Research on Cancer, Lyon, 1994, pp. 177-241.

9. Kawachi T, Kurisu M, Numanyu N, Sasajima K, Sano T. Precancerous changes in the stomach. Cancer Res 1976;36:2673-7.

10. Matsukura N, Suzuki K, Kawachi T, Aoyagi M, Sugimura T, Kitaoka H, et al. Distribution of marker enzymes and mucin in intestinal metaplasia in human stomach and relation to complete and incomplete types of intestinal metaplasia to minute gastric carcinomas. J Natl Cancer Inst 1980;65:231-40. 
11. Morson BC. Carcinoma arising from areas of intestinal metaplasia in the gastric mucosa. Br J Cancer 1955;9:377-85.

12. Filipe MI, Ramachandra S. The histochemistry of intestinal mucins: changes in disease. In: Whitehead R, editor. Gastrointestinal and oesophageal pathology. Edinburgh: Churchill Livingstone; 1995. p. 73-95.

13. Filipe MI, Potet F, Bogomoletz WV, Dawson PA, Fabiani B, Chauveinc $\mathrm{P}$, et al. Incomplete sulphomucin-secreting intestinal metaplasia for gastric cancer. Preliminary data from a prospective study from three centres. Gut 1985;26:1319-26.

14. Filipe MI, Munoz N, Matko I, Kato I, Pompe-Kirn V, Jutersek A, et al. Intestinal metaplasia types and the risk of gastric cancer: a cohort study in Slovenia. Int J Cancer 1994;57:324-9.

15. Matsukuma A, Mori M, Enjoji M. Sulphomucin-secreting intestinal metaplasia in the human gastric mucosa. An association with intestinal-type gastric carcinoma. Cancer 1990;66:689-94.

16. Rokkas T, Filipe MI, Sladen GE. Detection of an increased incidence of early gastric cancer in patients with intestinal metaplasia type III who are closely followed up. Gut 1991;32:1110-3.

17. Silva S, Filipe MI. Intestinal metaplasia and its variants in the gastric mucosa of Portuguese subjects: a comparative analysis of biopsy and gastrectomy material. Hum Pathol 1986;17:988-95.

18. You WC, Blot WJ, Li JY, Chang YS, Jin ML, Kneller R, et al. Precancerous gastric lesions in a population at high risk of stomach cancer. Cancer Res 1993;53:1317-21.

19. Stemmermann GN. Intestinal metaplasia of the stomach. A status report. Cancer 1994;74:556-64.

20. Kato Y, Kitagawa T, Yanagisawa A, Kubo K, Utsude T, Hiratsuka H, et al. Site-dependent development of complete and incomplete intestinal metaplasia types in the human stomach. Jpn J Cancer Res 1992;83:178-83.

21. Lauren P. The two histological main types of gastric carcinoma: diffuse and so-called intestinal-type carcinoma: an attempt at a histo-clinical classification. Acta Pathol Microbiol Scand 1965;64: 31-49.

22. Yuasa Y. Control of gut differentiation and intestinal-type gastric carcinogenesis. Nat Rev Cancer 2003;3:592-600.

23. Kusakabe M, Yokoyama M, Sakakura T, Nomura T, Hosick HL, Nishizuka Y. A novel methodology for analysis of cell distribution in chimeric mouse organs using a strain specific antibody. J Cell Biol 1988;107:257-65.

24. Tatematsu M, Fukami H, Yamamoto M, Nakanishi H, Masui T, Kusakabe N, et al. Clonal analysis of glandular stomach carcinogenesis in $\mathrm{C} 3 \mathrm{H} / \mathrm{HeN}\langle-\rangle \mathrm{BALB} / \mathrm{c}$ chimeric mice treated with $\mathrm{N}$ methyl-N-nitrosourea. Cancer Lett 1994;83:37-42.

25. Tatematsu M, Masui T, Fukami H, Yamamoto M, Nakanishi H, Inada $\mathrm{K}$, et al. Primary monoclonal and secondary polyclonal growth of colon neoplastic lesions in $\mathrm{C} 3 \mathrm{H} / \mathrm{HeN}\langle-\rangle \mathrm{BALB} / \mathrm{c}$ chimeric mice treated with 1,2-dimethylhydrazine: immunohistochemical detection of $\mathrm{C} 3 \mathrm{H}$ strain-specific antigen and simple sequence length polymorphism analysis of DNA. Int J Cancer 1996;66:234-8.

26. Tsukamoto T, Yamamoto M, Fukami H, Yoshikawa A, Sakai $\mathrm{H}$, Hirata A, et al. Susceptibility to colon carcinogenesis in $\mathrm{C} 3 \mathrm{H}$ $\langle-\rangle$ C57BL/6 chimeric mice reflects both tissue microenvironment and genotype. Cancer Lett 2006 (in press).

27. Fialkow PJ. Clonal origin of human tumors. Biochim Biophys Acta 1976;458:283-321.

28. Kakizoe T, Tanooka H, Tanaka K, Sugimura T. Single-cell origin of bladder cancer induced by N-butyl-N-(4-hydroxybutyl) nitrosamine in mice with cellular mosaicism. Gann 1983;74: $462-5$.

29. Nomura S, Kaminishi M, Sugiyama K, Oohara T, Esumi H. Clonal analysis of isolated intestinal metaplastic glands of stomach using X-linked polymorphism. Gut 1998;42:663-8.

30. Winton DJ, Blount MA, Ponder BA. A clonal marker induced by mutation in mouse intestinal epithelium. Nature 1988;333:463-6.

31. Park HS, Goodlad RA, Wright NA. Crypt fission in the small intestine and colon. A mechanism for the emergence of G6PD locus-mutated crypts after treatment with mutagens. Am J Pathol 1995;147:1416-27.

32. Potten CS. Stem cells in gastrointestinal epithelium: numbers, characteristics and death. Philos Trans R Soc Lond B Biol Sci 1998:353:821-30.

33. Katsuyama T, Spicer SS. Histochemical differentiation of complex carbohydrates with variants of the concanavalin Ahorseradish peroxidase method. J Histochem Cytochem 1978;26: 233-50.

34. Tatematsu M, Katsuyama T, Fukushima S, Takahashi M, Shirai T, Ito N, et al. Mucin histochemistry by paradoxical concanavalin A staining in experimental gastric cancers induced in Wistar rats by $\mathrm{N}$-methyl-N-nitro-N-nitrosoguanidine or 4-nitroquinoline 1oxide. J Natl Cancer Inst 1980;64:835-43.

35. Furihata C, Tatematsu M, Miki K, Katsuyama T, Sudo K, Miyagi $\mathrm{N}$, et al. Gastric- and intestinal-type properties of human gastric cancers transplanted into nude mice. Cancer Res 1984;44:727-33.

36. Tatematsu M, Furihata C, Katsuyama T, Mera Y, Inoue T, Matsushima $\mathrm{T}$, et al. Immunohistochemical demonstration of pyloric gland-type cells with low-pepsinogen isozyme 1 in preneoplastic and neoplastic tissues of rat stomachs treated with N-methyl-N'-nitro-N-nitrosoguanidine. J Natl Cancer Inst 1987; 78:771-7.

37. Tatematsu M, Katsuyama T, Furihata C, Fukushima S, Shirai T, Kato T, et al. Cellular differentiation and histogenesis of rat glandular stomach cancers. Jpn J Cancer Res 1990;81:760-7.

38. Iwata H, Itzkowitz SH, Werther JL, Hayashi K, Nakamura H, Ichinose $\mathrm{M}$, et al. Expression of sialosyl-Tn in intestinal type cancer cells of human gastric cancers. Acta Pathol Jpn 1993;43: $646-53$.

39. Inada K, Nakanishi H, Fujimitsu Y, Shimizu N, Ichinose M, Miki $\mathrm{K}$, et al. Gastric and intestinal mixed and solely intestinal types of intestinal metaplasia in the human stomach. Pathol Int 1997;47: 831-41.

40. Inada K, Tanaka H, Nakanishi H, Tsukamoto T, Ikehara Y, Tatematsu K, et al. Identification of Paneth cells in pyloric glands associated with gastric and intestinal mixed-type intestinal metaplasia of the human stomach. Virchows Arch 2001;439:14-20.

41. Tajima Y, Shimoda T, Nakanishi Y, Yokoyama N, Tanaka T, Shimizu K, et al. Gastric and intestinal phenotypic marker expression in gastric carcinomas and its prognostic significance: immunohistochemical analysis of 136 lesions. Oncology 2001;61:212-20.

42. Kawachi T, Kogure K, Tanaka N, Tokunaga A, Sugimura T. Studies of intestinal metaplasia in the gastric mucosa by detection of disaccharidases with "Tes-Tape". J Natl Cancer Inst 1974;53: 19-30.

43. Teglbjaerg PS, Nielsen HO. "Small intestinal type" and "colonic type" intestinal metaplasia of the human stomach, and their relationship to the histogenetic types of gastric adenocarcinoma. Acta Pathol Microbiol Scand [A] 1978;86A:351-5.

44. Segura DI, Montero C. Histochemical characterization of different types of intestinal metaplasia in gastric mucosa. Cancer 1983; 52:498-503.

45. Jass JR, Filipe MI. A variant of intestinal metaplasia associated with gastric carcinoma: a histochemical study. Histopathology 1979;3:191-9.

46. Karam SM, Leblond CP. Dynamics of epithelial cells in the corpus of the mouse stomach. I. Identification of proliferative cell types and pinpointing of the stem cell. Anat Rec 1993;236:259-79.

47. Ponder BA, Schmidt GH, Wilkinson MM, Wood MJ, Monk M, Reid A. Derivation of mouse intestinal crypts from single progenitor cells. Nature 1985;313:689-91.

48. Hattori T, Fujita S. Tritiated thymidine autoradiographic study of cell migration and renewal in the pyloric mucosa of golden hamsters. Cell Tissue Res 1976;175:49-57.

49. Yuasa $\mathrm{H}$, Inada $\mathrm{K}$, Watanabe $\mathrm{H}$, Tatematsu M. A phenotypic shift from gastric-intestinal to solely intestinal cell types in intestinal metaplasia in rat stomach following treatment with X-rays. J Toxicol Pathol 2002;15:85-93. 
50. Nozaki K, Shimizu N, Tsukamoto T, Inada K, Cao X, Ikehara Y, et al. Reversibility of heterotopic proliferative glands in glandular stomach of Helicobacter pylori-infected Mongolian gerbils on eradication. Jpn J Cancer Res 2002;93:374-81.

51. Yamamoto $M$, Furihata $C$, Ogiu $T$, Tsukamoto $T$, Inada $\mathrm{K}$, Hirano K, et al. Independent variation in susceptibilities of six different mouse strains to induction of pepsinogen-altered pyloric glands and gastric tumor intestinalization by N-methyl-Nnitrosourea. Cancer Lett 2002;179:121-32.

52. Mallo GV, Rechreche H, Frigerio JM, Rocha D, Zweibaum A, Lacasa M, et al. Molecular cloning, sequencing and expression of the mRNA encoding human Cdx1 and Cdx2 homeobox. Downregulation of $\mathrm{Cdx} 1$ and $\mathrm{Cdx} 2 \mathrm{mRNA}$ expression during colorectal carcinogenesis. Int J Cancer 1997;74:35-44.

53. Silberg DG, Furth EE, Taylor JK, Schuck T, Chiou T, Traber PG. CDX1 protein expression in normal, metaplastic, and neoplastic human alimentary tract epithelium. Gastroenterology 1997;113: 478-86.

54. Mizoshita T, Inada K, Tsukamoto T, Kodera Y, Yamamura Y, Hirai T, et al. Expression of $\mathrm{Cdx} 1$ and $\mathrm{Cdx} 2 \mathrm{mRNAs}$ and relevance of this expression to differentiation in human gastrointestinal mucosa - with special emphasis on participation in intestinal metaplasia of the human stomach. Gastric Cancer 2001;4:185-91.

55. Eda A, Osawa H, Yanaka I, Satoh K, Mutoh H, Kihira K, et al. Expression of homeobox gene CDX2 precedes that of CDX1 during the progression of intestinal metaplasia. J Gastroenterol 2002;37:94-100.

56. Satoh K, Mutoh H, Eda A, Yanaka I, Osawa H, Honda S, et al. Aberrant expression of CDX2 in the gastric mucosa with and without intestinal metaplasia: effect of eradication of Helicobacter pylori. Helicobacter 2002;7:192-8.

57. Drummond F, Sowden J, Morrison K, Edwards YH. The caudaltype homeobox protein $\mathrm{Cdx}-2$ binds to the colon promoter of the carbonic anhydrase 1 gene. Eur J Biochem 1996;236:670-81.

58. Suh E, Chen L, Taylor J, Traber PG. A homeodomain protein related to caudal regulates intestine-specific gene transcription. Mol Cell Biol 1994;14:7340-51.

59. Troelsen JT, Mitchelmore C, Spodsberg N, Jensen AM, Noren O, Sjostrom H. Regulation of lactase-phlorizin hydrolase gene expression by the caudal-related homoeodomain protein Cdx-2. Biochem J 1997;322(Pt 3):833-8.

60. Park J, Schulz S, Waldman SA. Intestine-specific activity of the human guanylyl cyclase $\mathrm{C}$ promoter is regulated by $\mathrm{Cdx} 2$. Gastroenterology 2000;119:89-96.

61. Yamamoto H, Bai YQ, Yuasa Y. Homeodomain protein CDX2 regulates goblet-specific MUC2 gene expression. Biochem Biophys Res Commun 2003;300:813-8.

62. Subramanian V, Meyer B, Evans GS. The murine Cdx1 gene product localises to the proliferative compartment in the developing and regenerating intestinal epithelium. Differentiation 1998; 64:11-8.

63. Lickert H, Domon C, Huls G, Wehrle C, Duluc I, Clevers H, et al. Wnt/beta-catenin signaling regulates the expression of the homeobox gene Cdx1 in embryonic intestine. Development 2000;127:3805-13.

64. Domon-Dell C, Freund JN. Stimulation of Cdx1 by oncogenic beta-catenin/Tcf4 in colon cancer cells; opposite effect of the CDX2 homeoprotein. FEBS Lett 2002;518:83-7.

65. Yuasa Y, Nagasaki H, Akiyama Y, Sakai H, Nakajima T, Ohkura $\mathrm{Y}$, et al. Relationship between $\mathrm{CDX} 2$ gene methylation and dietary factors in gastric cancer patients. Carcinogenesis 2005;26: 193-200.

66. Bowles J, Schepers G, Koopman P. Phylogeny of the SOX family of developmental transcription factors based on sequence and structural indicators. Dev Biol 2000;227:239-55.
67. Wood HB, Episkopou V. Comparative expression of the mouse Sox1, Sox2 and Sox3 genes from pre-gastrulation to early somite stages. Mech Dev 1999;86:197-201.

68. Ishii Y, Rex M, Scotting PJ, Yasugi S. Region-specific expression of chicken Sox2 in the developing gut and lung epithelium: regulation by epithelial-mesenchymal interactions. Dev Dyn 1998;213: 464-75.

69. Sakamoto N, Fukuda K, Watanuki K, Sakai D, Komano T, Scotting PJ, et al. Role for cGATA-5 in transcriptional regulation of the embryonic chicken pepsinogen gene by epithelialmesenchymal interactions in the developing chicken stomach. Dev Biol 2000;223:103-13.

70. Tsukamoto $\mathrm{T}$, Inada $\mathrm{K}$, Tanaka $\mathrm{H}$, Mizoshita $\mathrm{T}$, Mihara M, Ushijima $\mathrm{T}$, et al. Down regulation of a gastric transcription factor, Sox2, and ectopic expression of intestinal homeobox genes, Cdx1 and Cdx2: inverse correlation during progression from gastric/intestinal-mixed to complete intestinal metaplasia. J Cancer Res Clin Oncol 2004;130:135-45.

71. Li XL, Eishi Y, Bai YQ, Sakai H, Akiyama Y, Tani M, et al. Expression of the SRY-related HMG box protein SOX2 in human gastric carcinoma. Int J Oncol 2004;24:257-63.

72. Tsukamoto T, Mizoshita T, Mihara M, Tanaka H, Takenaka Y, Yamamura Y, et al. Sox2 expression in human stomach adenocarcinomas with gastric and gastric-and-intestinal-mixed phenotypes. Histopathology 2005;46:649-58.

73. Sakai H, Eishi Y, Li XL, Akiyama Y, Miyake S, Takizawa T, et al. PDX1 homeobox protein expression in pseudopyloric glands and gastric carcinomas. Gut 2004;53:323-30.

74. Faller G, Kirchner T. Immunological and morphogenic basis of gastric mucosa atrophy and metaplasia. Virchows Arch 2005;446: $1-9$.

75. Verrijzer CP, Van der Vliet PC. POU domain transcription factors. Biochim Biophys Acta 1993;1173:1-21.

76. Jin T, Li H. Pou homeodomain protein OCT1 is implicated in the expression of the caudal-related homeobox gene Cdx-2. J Biol Chem 2001;276:14752-8.

77. van den Brink GR, Hardwick JC, Nielsen C, Xu C, ten Kate FJ, Glickman J, et al. Sonic hedgehog expression correlates with fundic gland differentiation in the adult gastrointestinal tract. Gut 2002:51:628-33.

78. Kim JH, Huang Z, Mo R. Gli3 null mice display glandular overgrowth of the developing stomach. Dev Dyn 2005;234:98491.

79. Lund AH, van Lohuizen M. RUNX: a trilogy of cancer genes. Cancer Cell 2002;1:213-5.

80. Li QL, Ito K, Sakakura C, Fukamachi H, Inoue K, Chi XZ, et al. Causal relationship between the loss of RUNX3 expression and gastric cancer. Cell 2002;109:113-24.

81. Kim TY, Lee HJ, Hwang KS, Lee M, Kim JW, Bang YJ, et al. Methylation of RUNX3 in various types of human cancers and premalignant stages of gastric carcinoma. Lab Invest 2004;84:47984.

82. Osaki M, Moriyama M, Adachi K, Nakada C, Takeda A, Inoue Y, et al. Expression of RUNX3 protein in human gastric mucosa, intestinal metaplasia and carcinoma. Eur J Clin Invest 2004;34: 605-12.

83. Fukamachi H, Ito K, Ito Y. Runx3-/- gastric epithelial cells differentiate into intestinal type cells. Biochem Biophys Res Commun 2004;321:58-64.

84. Tanaka H, Tsukamoto T, Mizoshita T, Inada K, Ogasawara N, Cao X, et al. Expression of small intestinal and colonic phenotypes in complete intestinal metaplasia of the human stomach. Virchows Arch 2005;447:806-15. 